\title{
Autosomal recessive spastic ataxia with leukoencephalopathy
}

INSERM

\section{Source}

INSERM. (1999). Orphanet: an online rare disease and orphan drug data base. Autosomal recessive spastic ataxia with leukoencephalopathy. ORPHA:314603

A rare, genetic, autosomal recessive spastic ataxia disease characterized by cerebellar ataxia, spasticity, cerebellar (and in some cases cerebral) atrophy, dystonia, and leukoencephalopathy. 